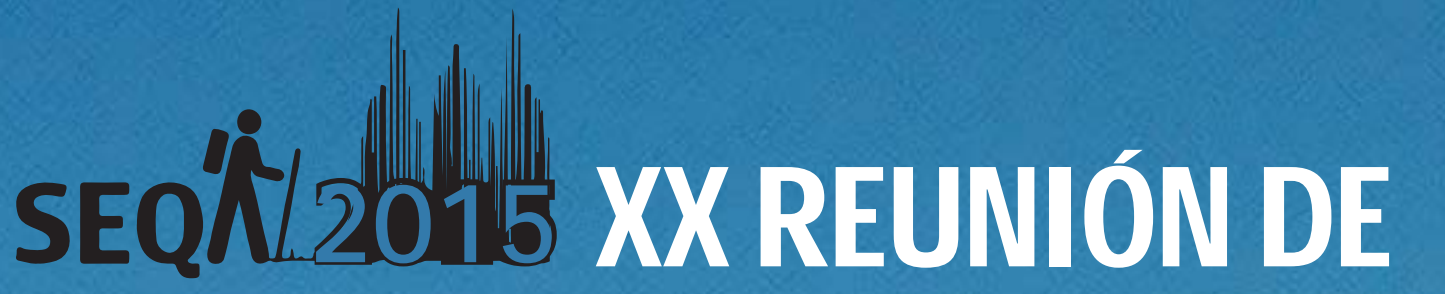

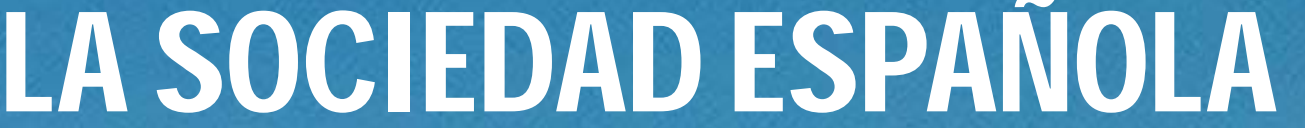 80
}

Santiago de Compostela • 01-03 de Julio de 2015

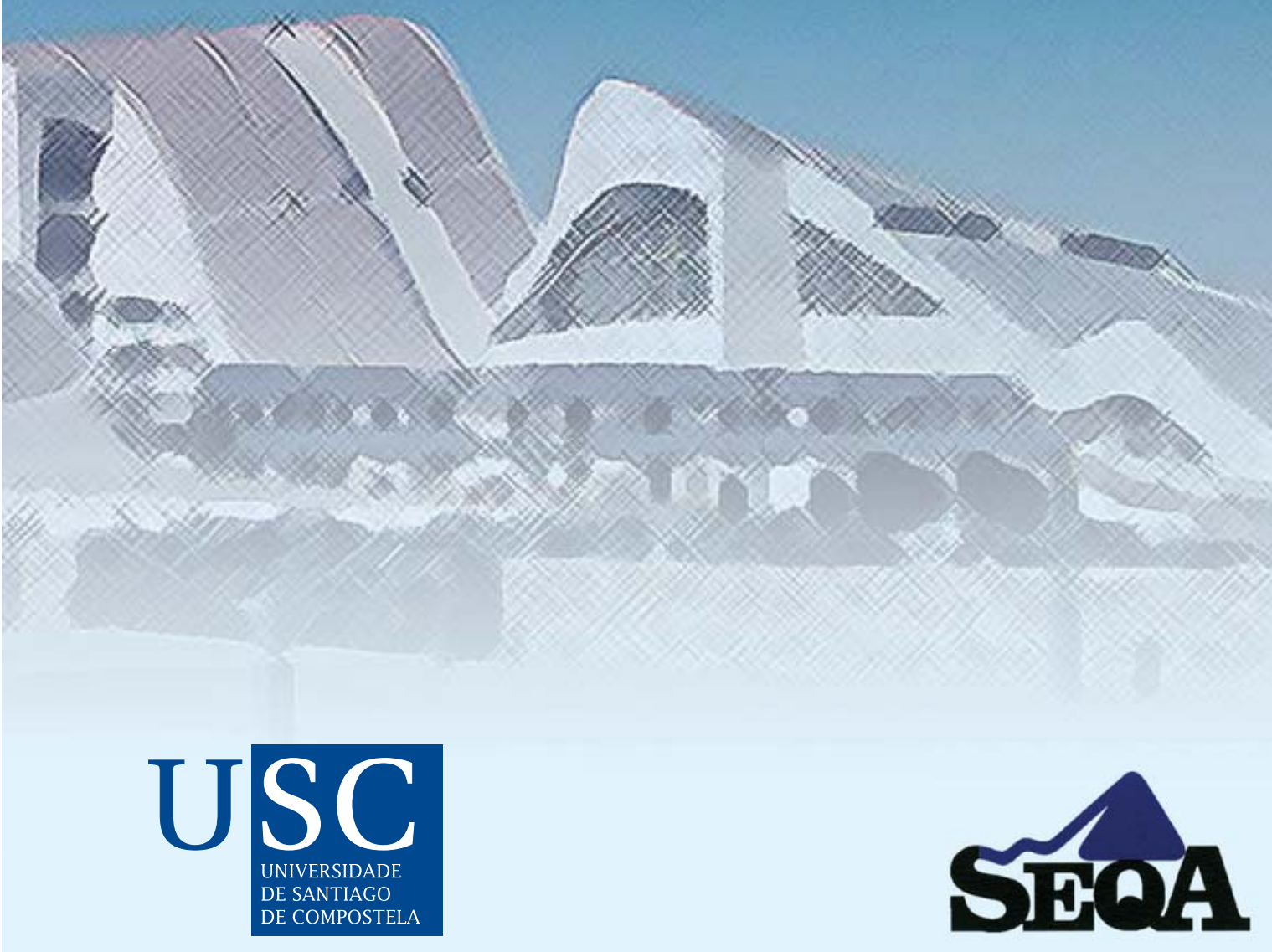




\begin{tabular}{|c|}
\hline SSID: SEQA \\
Login: SEQA \\
Password: wZeP1d/K \\
$\begin{array}{l}\text { Para acceder desde su portátil seleccione "SEQA" en las redes } \\
\text { inalámbricas disponibles. A continuación abra el navegador y escriba en } \\
\text { la página de identificación el Login y el Password que le proporcionamos }\end{array}$ \\
\hline
\end{tabular}

ISBN: 978-84-8408-867-7

DL: C 1221-2015 


\title{
ACCURACY EVALUATION OF ULTRASOUND PROBE SONICATION AND MICROWAVE- ASSISTED EXTRACTION SYSTEMS FOR RAPID SINGLE EXTRACTION OF METALS IN SOILS
}

\author{
David García-Casillas ${ }^{1}$, Sara García-Salgado ${ }^{1}$, M. Ángeles Quijano ${ }^{1}$
}

(1) Departamento de Ingeniería Civil: Hidráulica y Ordenación del Territorio, Escuela Técnica Superior de Ingeniería Civil, Universidad Politécnica de Madrid, C/ Alfonso XII, 3, 28014,

Madrid. Spain. e.-mail: marian.quijano@upm.es

The accumulation of metals in soils and sediments causes a potential risk to human health due to the transfer of these elements to other environmental compartments. However, metals are present in soils under different chemical forms or types of binding, so the total metal content is a poor indicator of their bioavailability, mobility or toxicity, since these properties basically depend on the chemical association of the different soil components. Therefore, the environmental impact of metalliferous soils is better assessed on the basis of the environmental accessibility of metals, i.e. the bioavailable forms for plants.

Harmonization of single extraction tests for the determination of extractable metals in soils has become of paramount importance, since they are used for discrimination of different solid-phase associations of metals in soils and sediments. Nevertheless, in the conventional extraction schemes, long extraction times by mechanical shaking and large quantities of samples and reagents are typically employed for the determination of the extractable metal content $[1,2]$.

In the present work, ultrasonic probe sonication (UPS) and microwave-assisted extraction (MAE) have been evaluated as alternatives to the conventional Standards, Measurements and Testing program (SM\&T) procedures for single extraction of metals in soils, in order to reduce the extraction time and the consumption of samples and extracting agents. Optimization studies were carried out on the certified reference materials (CRMs) BCR 483 (Sewage sludge amended soil) and BCR 700 (Organic rich soil) for accuracy evaluation of the proposed methods. Extractable concentrations of $\mathrm{Cd}, \mathrm{Cr}, \mathrm{Cu}, \mathrm{Ni}$ and $\mathrm{Zn}$ using $0.01 \mathrm{~mol} \mathrm{~L}^{-1}$ calcium chloride $\left(\mathrm{CaCl}_{2}\right)$ (in $\mathrm{BCR} 483$ ), and also of $\mathrm{Pb}$ with $0.43 \mathrm{~mol} \mathrm{~L}^{-1}$ acetic acid $\left(\mathrm{CH}_{3} \mathrm{COOH}\right.$ ) and $0.05 \mathrm{~mol} \mathrm{~L}^{-1}$ ethylenediaminetetraacetic acid (EDTA) at $\mathrm{pH} 7.0$ (in both CRMs) were determined by inductively coupled plasma atomic emission spectrometry (ICP-AES).

The extraction time for the $\mathrm{CaCl}_{2}$ extraction method was reduced from $3 \mathrm{~h}$ conventional procedure) to $2 \mathrm{~min}$ by UPS or $5 \mathrm{~min}$ at $50^{\circ} \mathrm{C}$ by MAE. Similarly, the time required for acetic acid extraction was also reduced from $16 \mathrm{~h}$ to $15 \mathrm{~min}$ by UPS or $15 \mathrm{~min}$ at $120^{\circ} \mathrm{C}$ by MAE. Finally, the extraction time with EDTA was reduced from $1 \mathrm{~h}$ (conventional procedure) to $2 \mathrm{~min}$ by UPS or $5 \mathrm{~min}$ at $50^{\circ} \mathrm{C}$ by MAE [3]. For these extraction conditions proposed, quantitative extraction recoveries were obtained for most elements studied. In addition, the amount of sample and extracting solutions was drastically reduced, maintaining the sample weight/extractant volume ratio.

References

[1] P. Quevauviller, G. Rauret, R. Rubio, J. F. López-Sánchez, A. Ure, J. Bacon, H. Muntau. Fresenius. J. Anal. Chem. 357 (1997) 611.

[2] M. Pueyo, G. Rauret, J. R. Bacon, A. Gómez, H. Muntau, P. Quevauviller, J. F. López-Sánchez. J. Environ. Monit. 3 (2001) 238.

[3] D. García-Casillas, S. García-Salgado, M. Á. Quijano., Anal. Method 6 (2014) 8403. 